\title{
Ethno-Cultural Differences and Consumer Understanding of Eco-Labels: An Empirical Study in Malaysia
}

\author{
Elham Rahbar \\ School of Management, Universiti Sains Malaysia, 11800, Penang, Malaysia \\ Tel: 60-1-2490-0742 E-mail: elham_3121@yahoo.com \\ Nabsiah Abdul Wahid (Corresponding author) \\ Graduate School of Business, Universiti Sains Malaysia, 11800, Penang, Malaysia \\ Tel: 60-1-2472-3183 E-mail: nabsiah@hotmail.com
}

This research project was funded by the Universiti Sains Malaysia fellowship scheme and the FRGS scheme. The authors thank the IPS and the School of Management for providing facilities.

\begin{abstract}
Firms have been using eco-label as a tool to inform consumers of the environmental characteristics of their products. The essential issue for marketers in international markets particularly in countries with multi-ethnic population such as Malaysia is to identify the existence of different ethnic groups and their responses (i.e. behavior) to their products. The purpose of this article is to examine whether different ethnic groups display different perception on eco-label. Results indicate that Malay, Chinese and Indian, the three major ethnic groups in Malaysia differ in their awareness, recognition and perception of the eco-label. The findings imply the importance of ethnicity whereby marketing managers should consider ethno-cultural differences when marketing and promoting their eco-labeled products in the market to achieve competitive advantage.
\end{abstract}

Keywords: Eco-label, Ethnic groups, Malaysia

\section{Introduction}

With the emergence of environmental marketing, focus was laid on the study of the marketing tools (e.g. eco-label and eco-brand) that may link the environmental products to consumers in the marketplace. As the market is heterogeneous in nature, there is a need to segment the huge market into smaller and manageable markets. To date, marketers utilize several methods to segment potential markets. The main segmentation tools that have been carried out include consumer's demographics such as age, income, gender and ethnicity. Despite numerous researches that define consumers' demographic in US and European markets very little is known about consumers' purchase behavior in Asian region. The Asian region is diverse in terms of ethnic groups with different perceptions and behaviors and own distinct cultures. The business environment is also dissimilar from the western countries. Keegan and Green (2000) noted that without adequate market information in Asian countries, global environmental marketers will fail in their effort to access competitive advantage and their marketing strategies. Malaysia, as part of the Asian countries boasts three main ethnic groups i.e. Malay, Chinese and Indian; thus there is a need to find out whether ethnic influences exist. The objective of this study is to determine the level of consumers' perception of eco-label and investigate whether this perception is different between various ethnic groups in Malaysia.

\section{Literature Review}

\subsection{Ethnicity Variation in Malaysia}

As examination of ethno-cultural differences are required for this study, the researchers starts this section with a brief review on the three major Malaysian ethnic groups (Malay, Chinese and Indian) to assist us to understand the possible linkage between Malaysia ethno-cultural values and their perception about eco-label.

Malaysia is one of the most culturally diverse nations in Asia. Malaysia's multi-racial society contains many ethnic groups. According to the Department of Statistics Malaysia (2009), Malaysia's population as of July 2009, was estimated at 28.31 million. Malay dominates with a majority of just over $50 \%$. By constitutional definition, all Malays are Muslim. About a quarter of the population is Chinese (26\%), an ethnic group that play important role in the country's trade and business. Indian comprises about 7\% of the Malaysian population. The ethnic group includes members with various religions such as Hindu, Islam, Buddha, and Christian. The combined non-Malay indigenous groups make up approximately $11 \%$ of the country's population (Department of Statistics Malaysia , 2009).

Majority of Chinese and Indian who live in Malaysia are Malaysia-born. Malaysian Chinese for example is a Malaysian of Chinese origin. Most are descendants of Chinese from China who arrived in the country between the fifteenth and the mid-twentieth centuries. Within Malaysia, they are usually simply referred to as "Chinese" in all languages. The term Chinese Malaysian is also sometimes used to refer to this community. Malaysian Indians are Malaysian with Indian origin. The group largely descended from those who migrated from southern India during the British colonization of Malaya before Independence Day. Prior to British, Tamils had been conspicuous in the Archipelago much earlier, especially since the period of the powerful south India kingdom of 
the Cholas in the 11th century. By that time, Tamils were among the most important traders of maritime Asia (Sneddon \& James, 2003).

Weber (1986) believed ethnicity as a stable trait that is inheritable driven from a common descent. However, Zmud \& Arce (1992) viewed ethnicity as both stable and varying characteristic. They stated that ethnicity functions in two discrete modes i.e. cultural identity (stable manner) and social identity - which vary with the social surrounding. In anthropological expression, social identity refers to the fact of acculturation. As Sabatier \& Berry (1996) pointed out, acculturation has been considered as a progressive adaptation when people separate from their group of origin to join the dominant host society. Similarly, Navas, Rojas, Garcia, \& Pumares (2007) state acculturation as way immigrants wish to keep their own identity and simultaneously connect to other groups in the host society or ways of life in the new society. Orientation towards the group of origin or towards the host society is, according to this perspective. Orientation towards the group of origin or towards the host society follows this perspective. According to Liu (2007), minority groups and individuals would attempt to shift from their conventional lifestyle to a way similar to the host society, resulting the emergence of a multidimensional view of acculturation melting pot notion to the society.

\subsection{Perception of Eco-Label}

The increase in the number of organizations claiming to be environmental related have seen many firms attempting to identify their eco-friendly products by distinctive methods to consumers in the marketplace. One of the effective strategies in green marketing implemented today is via the use of eco-labels to make consumers aware of the environmental performance of the products.

Eco-labels refer to the main tools of green marketing that will help consumers make decisions about specific product choices; information that tell them that the product will reduce impact on the environment and facilitate them to be aware of the product's production procedure (Rex \& Baumann, 2007). Childs \& Whiting (1998) simply considered eco-labels as indicators of the environmental performance of a product.

Throughout the years, Malaysia has shown serious commitment towards environmental management to achieve environmental objectives. An example is the launching of the Product Certification Program, Malaysia's national labeling program by the Standards and Industrial Research Institute of Malaysia (SIRIM) in 1996. This eco-labeling scheme functions as information provider for consumers at large on how to identify environmental products and their specifications. Other considerable national environmental policies which are endorsed by the Agricultural Department and Federal Agriculture Marketing Authority (FAMA) and the Malaysian Energy Commission are related to agricultural products and energy efficiency (EE) respectively. The developments observed in Malaysia show the efforts taken through green marketing initiatives by the government and many parties to encourage Malaysian consumers into taking account the environmental aspects in their purchasing behavior.

\subsection{Perception of Eco-Label and Ethnicity Variation}

Many factors influence individuals in their decision purchase and consumption. Ethnicity and culture is one of the important factors that may impact on consumers' behaviors and perception. Individuals from different ethnic background perceive environmental problems in different ways and behave distinctively to solve the problem. For example, they may consider eco-labeling scheme and other green marketing strategies to be different from one another, thus, their perception, decision making and behavior on each may be dissimilar as well.

As the objective of the present study is to examine whether the different Malaysian ethnic groups (who display different ethno-cultures) differ on their perception of the eco-labeling scheme, a discussion of how different ethic groups with different cultures may shape Malaysian consumers' views on the natural environment is considered essential.

Johnson, Bowker \& Cordell (2004) emphasized on examining the environmental view and behavior of different ethnics of a population. As Macnaghten \& Urry (1998) argued, people's responses to nature are derived from specific social practices in particular from practices in their residencies which produce diverse nature and values. According to Altman \& Chemers (1980), the traditional Eastern cultures consider humans harmonious relationship with nature. For example, Chan (2001) emphasized on the traditional Chinese man-nature orientation and collectivism as factors that help form Chinese consumers' environmental attitude, perception and behavior. The Chinese in Malaysia has been observed to specifically emphasize on living in harmony with nature. According to Chan \& Lua (2000), the Chinese follows Toaist philosophy that man's relationship with nature is to maintain, rather than to master it. The Indians (the third largest ethnic group in Malaysia) believe on the philosophy that nature are created by God and thus, deserve the same respect as humans do. And from there developed the concept of being vegetarian and respect for all living beings, the concept which is so unfamiliar to Western society which believes in Capitalism, Materialism and Consumerism. The Malays, who are strictly bound by Islam as their religion, also display similar man-nature orientation and respect for both nature and humans alike as the Chinese and Indians based on their religion's regulations although the belief does not made them vegetarians as the Indians. From the foregoing discussion, it seems that there is not one distinct environmental orientation held by any of the ethnic groups in Malaysia which leads to the important question on 
the likelihood for consumers with similar or same environmental orientation to show similar response(s) to eco-label.

As earlier mentioned, eco-label is known as an essential marketing tool to assist consumers in identifying green products in the marketplace. In general, product labels offer an informative base to individuals to make a conscious choice (D'Souza, Taghian, \& Lamb, 2006).

A review of the literature revealed that issues associated with ethnicity and their perception and environmental purchase behavior are popular topics among researchers. A number of researchers have identified ethnicity as a significant factor in perception of eco-label. For example, Lin (2009) found significant association between ethnicity and organic cotton preference in Hawaii. Howard \& Allen (2006) found that in the case where labels were preferred overall by respondents, distinctive differences can still be distinguished based on gender, ethnicity and other variables. The result of Nik Ramli, Jusoff, \& Kassim's (2009) study in Malaysia indicated that Malaysian consumers would certainly react positively to the eco-label. Shen's (2008) study in China revealed that for Chinese consumers who believed in environmental protection and further believed that it is as an essential issue, they take into account purchasing the eco-labeled products and are also willing to pay more for those products with environmental label or eco-label.

The purpose of this article is to provide an overview on eco-labeling perception of different ethnic groups in Malaysia and present useful information for local and international green marketing firms on how to position their eco-labeled products between varieties of ethnicity in Malaysia.

\section{Method}

\subsection{Sampling Design}

The essential part of data collection is sampling design. Selecting the appropriate sampling method would enable researchers to generalize their finding and sample's elements characteristics to the population elements (Sekaran 2006).

\subsection{Sampling Procedure and Data Collection}

The unit of analysis for this study is consumers in Penang (one of the 14 states in Malaysia). The quota sampling was applied as the sampling method to ensure the diversity of ethnics in Malaysia; in particular Penang state is covered. It is considered a proper method for this study to distinguish the perception of eco-label between different races.

The individual consumers who act as respondents were those who live in Penang and aged over 18 years of age. The reason is, people above this age are familiar with purchase of products and are empowered in their decisions to choose the right items between so many available choices. Therefore, they are enough wise in their decision making and recognition, thereby, findings would be representative. The population percentage of ethnic groups as it exhibits in Figure 1, are $42.57 \%$ Chinese, $41.40 \%$ Malay, $9.92 \%$ Indian and $6.12 \%$ other races. The sampling elements were conducted according to the above percentages. Thus, both Malay and Chinese respondents were $40 \%$ followed by $10 \%$ Indian and $10 \%$ from other ethnic groups.

Data collection was carried out by distributing a set of questionnaires in two major shopping centers in Penang where people purchase their daily necessities (mall intercept) and also Universiti Sains Malaysia (in Malay language). USM is a proper place to conduct the survey due to its variety in age and education of respondents. Hence, by including these three places in the survey, it was hoped the findings can be generalized to whole consumers in Penang. A total of 250 persons in Penang participated in this study.

The collection method carried out at the two shopping malls was done as follows: the researcher tried to identify the race of the respondents through observation and if there was doubt in their ethnic background, the researchers will ask them to confirm their ethnic group. Once identified, permission was asked from respondents to take part in the study. The researchers then explained briefly about purpose of the study to respondents once they agreed to be a volunteer.

\subsection{Measurement Instrument}

The perception of eco-label as a helpful tool for consumers to recognize environmentally- friendly products, was adapted from Nik Ramli (2007). The original instrument consists of three components of evaluation consumer's cognitive toward the eco-label which is: awareness, knowledge and trust. In respect to subject of study, researchers preferred to adopt just two parts, awareness and trust, with five-point Likert scale composed of three items respectively.

The local eco-label (Malaysian Best) was chosen for this study to ensure a logo selected is familiar to respondents to avoid bias research findings. A brief description of the Malaysian's best eco-label is provided in Table 1.

Two items of this section were negatively worded (e.g. I am doubtful of MB logo). Hence, throughout the data key in process, the values were reverse coded to ensure accuracy of analysis. 


\section{Findings}

\subsection{Respondents Profile}

The profile of respondents include, age, gender, marital status, ethnicity, educational level, monthly income, and place of stay.

The majority of the respondents were female (63\%), in term of age, the average age were 30 years old, $63 \%$ were single and most of them have had education at bachelor degree (40\%). The averages of respondents' monthly income were $1325 \mathrm{RM}$ and $84 \%$ were from urban area.

\subsection{ANOVA Test}

To determine whether the differences between means for the four ethnic groups (Malay, Chinese, Indian, other ethnicities) of eco-label perception were significant, one-way ANOVA test was conducted. In addition, in look for the research objectives, descriptive statistics, including means and standard deviations, of the constructs were performed.

Based on the descriptive results indicated in Table 2, there is a significant difference in the mean perception of eco-label in the four ethnic groups. The results of the mean perception of eco-label for the four groups show that Malay has a higher mean value compared to Chinese, Indian and other ethnic groups (3.17, 2.71, 2.96, and 2.62 respectively). The Malays as an ethnic group, is significantly different from Chinese and Indians with respect to perception of eco-label.

Prior to conducting the ANOVA test for the three ethnic groups, Levene's test to examine whether the homogeneity assumption has not been violated was carried out. The results of the Levene's test showed a value at 1.547 with 2 degrees of freedom. In addition, the homogeneity of variance was not significant $(0.927, P<0.05)$, thus the population variance for each group was approximately equal. Since the one-way ANOVA did not indicate which groups to be statistically different, the post hoc tests were used to assess differences between groups. As indicated in Table 2 results, only mean comparison between Malay and Chinese showed a difference in value (0.46), while, a comparison between Chinese, Indian and other ethnic groups did not show any difference. In general, the one-way ANOVA indicates a significant difference between the four groups (i.e. the Malay group was found to be different from the Chinese in their perception of eco-label levels with the Malay perception to be generally higher than the rest).

Table 3 provides descriptive results of the four ethnic groups in terms of their means, standard deviation and standard error for comparison. To further explore differences between four ethnic groups besides perception and recognition of eco-label, one way ANOVA Duncan test procedures were used. Consumers were asked to indicate their:

- Awareness on eco-label;

- Recognition of eco-label;

- Familiarity with Malaysian Best eco-label;

- Belief of eco-labels as a symbol of product reliability;

- Trust on eco-label; and

- Doubts on eco-label.

The results of the mean values of consumers' perception towards eco-label, show differences (Table 4). For instance, many consumers believe eco-label to be the symbol of product reliability. For these consumers, they also trust the green strategy and rely on it to make purchase decisions of green products. However, others indicate their unfamiliarity with the eco-label.

Among all six items of eco-label measured, the difference in perception of eco-label appears to be more in their awareness of eco-label. This result is displayed in Table 5 where the Malay displays different level of awareness compared to the other groups measured in the study (i.e. Chinese, Indians and other). The result indicates that the Malays are more aware of eco-label than the other three groups of ethnicity. Therefore, the results for other five items do not indicate any differences between ethnic groups.

\section{Discussion and Implication}

This finding implies the fact that Malaysian consumer markets can be segregated according to ethnic groups such as Malay, Chinese and Indian. The market is not homogenous. The findings of this study showed that the consumers' perceptions are different between various ethnics in Penang which can be a proxy to the general Malaysian market (refer to Table 2). The present findings may provide guidance to organizations that sells and promote green products. It implies the impossibility for the companies in different industries to treat the consumers as a broad single homogenous market. This is because consumers vary in segments according to factors such as ethnic groups. In Malaysia, the ethnic groups display different culture and religion which may also be influencing factors in the purchase decisions of green products. 
The results from one-way ANOVA to test differences between ethnic groups show Malays to be different from the other three ethnic groups in terms of their level of awareness. In fact, with a mean value of 3.17, the Malays show the highest mean value amongst the four groups tested. The difference may be due to the fact that the Malays, by virtue of their religion needs, more consider to labels on products. For example, they are more attentive and display concerns over 'halal' labels. This subject led them to attention to labels more than Chinese and Indian. Hence, they recognize label and can roughly trust to that as an informative tool to help them decide on their product purchase. The findings are similar to Nik Ramli's (2009). In his study, Nik Ramli (2009) stated that when consumers with high level of awareness of the eco-label are confronted by a purchase decision making situation, they would simply distinguish between green products and ordinary products. Taking this view into the current study, the perception made may the reason for why the Malays are found to express a higher eco-label perception than Chinese, Indian and other ethnic groups.

The results also revealed that there are not any differences between ethnic groups in terms of their trust to eco-label and they believe Malaysian Best (eco-label) is truthful (mean, 3.35). This result is consistent with previous study that has explored Malaysian consumer trust to eco-label and the influence it has in their choice for the corresponding environment friendly product (Nik Ramli, 2009).

The findings highlight of correct identification of market segments by companies so that they can cater and serve effectively to specific target market of their environmentally friendly products. Such decision requires complete understanding of different market segments in the marketplace, in particular their perception and behavior towards environmentally friendly products so that suitable strategies can be designed to tailor to their needs (e.g. preference). For example, manufacturers can produce different forms of green products in terms of their price and quality, depending on various ethnic groups' preferences and their differences in income.

\section{Conclusion}

Overall, the findings of the present study suggest that there have been significant differences on ethic groups' perception toward eco-label. In addition, ethnic group (Malays) who are more aware of eco-label would have the stronger perception for eco-label. The study suggests that companies selling and promoting green products should concentrate on the Malays as their target market in Malaysia rather than the other ethnic groups if they are using eco-label as their marketing tool. In order to enhance other ethnic groups in Malaysia, green marketers have to find other green marketing means to attract the Chinese, Indians and other group. Providing more information about benefits of eco-labeled products and impact of them on environment would help other ethnic groups to be familiar with eco-label and consideration of that in their purchase decisions.

Consequently, appreciation of similarities and differences can enhance green marketers' understandings and their international counterparts to improved cross-national working relationships.

This research has certain limitations. Despite the similarity within ethnic groups, it would be difficult to generalize the results of this study to Malay, Chinese and Indian in other countries due to acculturation issue that elucidated in literature review. There is need to further research in different country with the same ethnic and cultural context.

\section{References}

Altman, I., Chemers, M. (1980). Culture and environment. Monterey, CA: Brooks \& Cole Publishing Co.

Chan, R. Y., \& Lua, L. B. (2000). Antecedents of green purchases: a survey in China. Journal of Counsumer Marketing , 17 (4), 338-357.

Chan, R. Y. (2001). Determinants of Chinese Consumers' Green Purchase Behavior. Psychology\& Marketing , $18(4), 389-413$.

Childs, C. \& Whiting, S. (1998). Eco-labeling and the Green Consumers. Working papers from Sustainable Business Publications series. The Sustainable Business Initiative, Department of Environmental Science, University of Bradford, West Yorkshire. [Online] Available:http://www.brad.ac.uk/acad/envsci/SB/init.htm.

D'Souza, C., Taghian, M., \& Lamb, P. (2006). An empirical study on the influence of environmental labels on consumers. Corporate Communications: An International Journal , 11 (2), 162-173.

D'Souza, C., Taghian, M., Lamb, P., \& Peretiatko, R. (2007). Green decisions: demographics and consumer understanding of environmental labels. International Journal of Consumer Studies , 31, 371-376.

Department of Statistics Malaysia . (2009, July 31). Retrieved 2010, from Department of Statistics Malaysia.

Howard, P. H., \& Allen, P. (2006). Beyond organic: consumer interest in new labelling schemes in the Central Coast of California. International Journal of Consumer Studies , 30 (5), 439-451.

Johnson, C. Y., Bowker, J. M., \& Cordell, H. K. (2004). Ethnic Variation in Environmental Belief and Behavior: An Examination of the New Ecological Paradigm in a Social Psychological Context. Environment and Behavior, 36, 157-186. 
Lin, S.-H. (2009). Exploratory evaluation of potential and current consumers of organic cotton in Hawaii. Asia Pacific Journal of Marketing and Logistics , 24 (4), 489-506.

Liu, S. (2007). Living with others: Mapping the routes to acculturation in a multicultural society. International Journal of Intercultural Relations , 31, 761-778.

Macnaghten, P., Urry, J. (1998). Contested natures. London: Sage.

Navas, M., Rojas, A. J., Garcia, M., \& Pumares, P. (2007). Acculturation strategies and attitudes according to the Relative Acculturation Extended Model (RAEM): The perspectives of natives versus immigrants. International Journal of Intercultural Relations, 31, 67-86.

Nik Ramli, N. A., Jusoff, K., \& Kassim, K. M. (2009). Eco-Labeling Perspectives amongst Malaysian Consumers. Canadian Social Science, 5 (2).

Nik Ramli, N.A.R., (2007). Employee involvement in EMS/ISO 14001 and its spillover effect in consumer environmentally responsible behavior, Universiti Sains Malaysia.

Rex, E., \& Baumann, H. (2007). Beyond ecolabels: what green marketing can learn from conventional marketing. Journal of Cleaner Production, 15, 567-576.

Sabatier, C., \& Berry, J. W. (1996). Inmigracio' n y aculturacio' n. In R. Y. Bourhis, \& J. Ph. Leyens (Eds.), Estereotipos, discriminacio'n y relaciones entre grupos (pp. 217-239). Madrid, Spain:McGraw-Hi 11.

Sekaran, U. (2000). Research methodology for business: A skill building approach. NewYork: John Wiley and Sons, Inc.

Shen, J. (DP-2008-E-001). Understanding the determinants of consumers' willingness to pay for eco-labeled products: An empirical analysis of the China Environmental Label. OSIPP Discussion Paper.

Sneddon, James (2003). The Indonesian Language: Its history and role in modern society. Sydney: University of South Wales Press Ltd. p. 73.

Thøgersen, J. (2002). Promoting "green” consumer behavior with eco-labels. In: T. Dietz \& P. C. Stern (Eds.), New Tools for Environmental Protection, pp. 83-104.Washington, DC: National Academy Press.

Zmud, J., \& Arce, C. (1992). The Ethnicity and consumption relationship. Advanced in Consumer Research, 19, 443-449.

[Online] Available: http://www.agnet.org/library/bc/54005 (May 1, 2010)

Table 1. Short description about Malaysian's Best Eco-Label

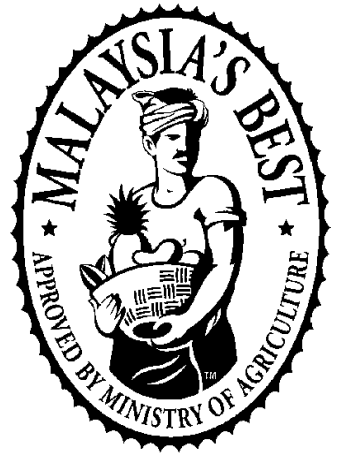

To date, the food safety is one of the essential issues to consumers. They consider so much to harmless of food they are eating, especially in terms of pesticide residues. Malaysia's Best" is a program of the Ministry of Agriculture and Agro-based Industry (MOA). Under this program, only the best produce meeting the requirements of "Malaysia's Best" standards can use "Malaysia's Best" logo, and the government will ensure the best price for these produce. Malaysian Farm Good Agricultural Practice Scheme (Salm) was launched on 31 January 2002 by the DOA. Besides the production of the food, the government is also concerned with the environment in terms of pesticide residues in the soil or on the rivers, as well as fertilizer run-off from the farms, whose overuse of nitrate fertilizers may cause environmental disaster.

nowadays, some fruit have been selected to test and government is promoting them under the Malaysia's Best logo. These fruits are mango, watermelon, papaya, pineapple and star fruit (Averrhoa carambola). Shortly, all agricultural produces, including fishes and animal meats will also are permitted to use the "Malaysia's Best" logo".

Source: http://www.agnet.org/library/bc/54005 accessed on 01/05/2010 
Table 2. Post hoc tests, Tukey HSD

\begin{tabular}{llrrrrr}
\hline Ethnics & & Mean Difference & Std. Error & Sig. & \multicolumn{2}{c}{$95 \%$ CI } \\
\cline { 5 - 7 } Malay & Chinese & $.46000^{*}$ & .14140 & .007 & .0943 & Lower Bound \\
& Indian & .21500 & .22357 & .771 & -.3633 & .79257 \\
& Others & .55500 & .22357 & .065 & -.0233 & 1.1333 \\
Chinese & Malay & $-.46000^{*}$ & .14140 & .007 & -.8257 & -.0943 \\
& Indian & -.24500 & .22357 & .692 & -.8233 & .3333 \\
& Others & .09500 & .22357 & .974 & -.4833 & .6733 \\
Indian & Malay & -.21500 & .22357 & .771 & -.7933 & .3633 \\
& Chinese & .24500 & .22357 & .692 & -.3333 & .8233 \\
& Others & .34000 & .28279 & .626 & -.3915 & 1.0715 \\
\multirow{3}{*}{ others } & Malay & -.55500 & .22357 & .065 & -1.1333 & .0233 \\
& Chinese & -.09500 & .22357 & .974 & -.6733 & .4833 \\
& Indian & -.34000 & .28279 & .626 & -1.0715 & .3915 \\
\hline
\end{tabular}

* The mean difference is significant at the .05 level.

Table 3. Descriptive analysis

\begin{tabular}{lrcrr}
\hline & \multicolumn{4}{c}{ Descriptives } \\
\hline Malay & 100 & 3.1750 & .97539 & .09754 \\
Chinese & 100 & 2.7150 & 1.00568 & .10057 \\
Indian & 25 & 2.9600 & .99917 & .19983 \\
others & 25 & 2.6200 & 1.07316 & .21463 \\
Total & 250 & 2.9140 & 1.01969 & .06449 \\
\hline
\end{tabular}

Table 4. Descriptive Statistics

\begin{tabular}{|c|c|c|c|c|c|}
\hline & $\mathrm{N}$ & Min & Max & Mean & $\begin{array}{c}\text { Std. } \\
\text { Deviation }\end{array}$ \\
\hline I am aware the MB eco-label & 250 & 1 & 5 & 2.84 & 1.142 \\
\hline $\begin{array}{l}\mathrm{MB}^{*} \text { eco-label is easily recognizable } \\
\text { for me }\end{array}$ & 250 & 1 & 5 & 2.98 & 1.053 \\
\hline I am unfamiliar with MB eco- label & 250 & 1 & 5 & 2.82 & 1.174 \\
\hline $\begin{array}{l}\text { MB logo is symbol of product } \\
\text { reliability }\end{array}$ & 250 & 1 & 5 & 3.40 & .868 \\
\hline I believe MB logo is truthful & 250 & 1 & 5 & 3.35 & .847 \\
\hline I am doubtful of the MB logo & 250 & 1 & 5 & 3.26 & .928 \\
\hline Valid N (listwise) & 250 & & & & \\
\hline
\end{tabular}

*MB: Malaysian Best eco-label 
Table 5. Duncan Test, I am aware the above eco-label

\begin{tabular}{cccc}
\hline & & \multicolumn{2}{c}{ Subset for alpha $=.05$} \\
\cline { 3 - 4 } Ethnicity & $\mathrm{N}$ & 1 & 2 \\
\hline Others & 25 & 2.40 & \\
Chinese & 100 & 2.60 & \\
Indian & 25 & 2.88 & \\
Malay & 100 & & 3.19 \\
Sig. & & .068 & .212 \\
\hline
\end{tabular}

Means for groups in homogeneous subsets are displayed.

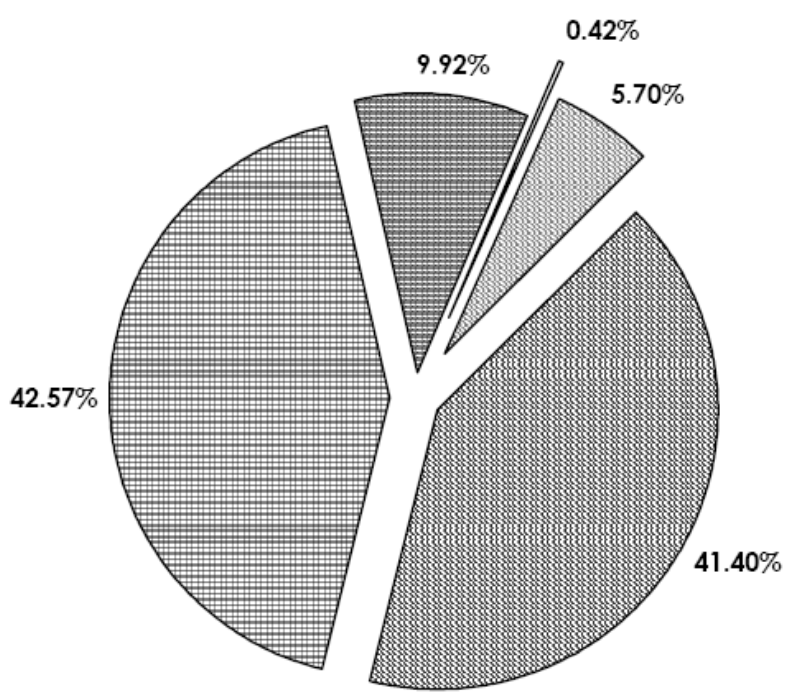

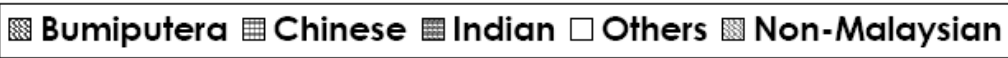

Source: Department Of Statistics, Penang (2006)

Figure 1. The Total Population of Penang under Ethnic groups 